\title{
EFFECT OF ROAD SURFACE DEFORMATIONS ON LATERAL LANE UTILIZATION AND LONGITUDINAL DRIVING BEHAVIOURS
}

\author{
Metin Mutlu Aydin ${ }^{1}$, Ali Topal ${ }^{2}$ \\ ${ }^{1}$ Dept of Civil Engineering, Akdeniz University, Turkey \\ ${ }^{2}$ Dept of Civil Engineering, Dokuz Eylül University, Turkey
}

Submitted 1 April 2015; resubmitted 10 July 2015, 18 September 2015; accepted 19 October 2015

\begin{abstract}
Various road surface deformations generally occur on urban and rural roads due to infrastructure, superstructure deficiencies and excessive heavy vehicle loads. In addition to driver-based errors, many accidents happen due to these mentioned surface deformations. This study aims to present lateral lane utilization and longitudinal driving behaviours on a two-lane deformed road. The effect of deformation on the tendency of drivers' lane selection, lane utilization, and the movement in traffic flow will also be determined. For this purpose, parameters such as lateral position, speed, acceleration/deceleration and location data of vehicles travelling through four different deformation zones on a two-lane road in Izmir (Turkey), were collected. Based on the fact that in ideal conditions, distribution of lateral positions of vehicles in a lane is similar to normal distribution. The collected data was evaluated with chi-square $\left(\chi^{2}\right)$ goodness of fit test to see if they are fit to normal distribution or not. This study concluded that if a deformation zone has wider area and less depth, it will be less effective on lateral lane utilization of vehicles. It was also obtained from the results that variation in other parameters such as deformation type, depth and height are associated with the lateral lane utilization of drivers. Additionally, the drivers' characteristics such as perception and aggressiveness are seen as the most important factors influencing the longitudinal vehicle behaviours while passing through the deformation zones.
\end{abstract}

Keywords: chi-square $\left(\chi^{2}\right)$ goodness of fit test; driver characteristics; road surface deformations; lane utilization; lateral and longitudinal vehicle locations.

\section{Introducion}

One of the most significant factor that affects lateral friction resistance, lateral and longitudinal positions of vehicles is road surface deformation. Surface deformations are defined as any change of a road according to the initial state of a road surface (Aydin et al. 2014). In addition, the surface deformations are a function of vertical depressions (potholes, rutting etc.) or deflections (road humps and speed cushions etc.) (Ben-Edigbe et al. 2011). Road pavements are designed based on an estimated traffic carrying capacity throughout a service life (Ben-Edigbe, Ferguson 2005). After the pavement surface begins its service life, various surface deformation types appear to form on the road surface in the form of potholes, broken edges, rutting, cracking, swelling and shoving. They are particularly observed at sections of the roads where the number of vehicles in traffic are excessive. Major reason for the deformation is the increase in interacting axle load depending on the number of vehicles using the mentioned parts of the road (Nagel,
Schreckenberg 1992; Leutzbach, Wiedemann 1986). In addition, their types on the road surface vary with the features of bituminous material used in road construction, traffic volume, environmental factors, and subgrade bearing capacity of pavement (Walker et al. 2002; Aydin et al. 2013). They may adversely affect the service ability of a road in relation with their position and size on the deformed road surfaces and work zones (Aydin 2013). However, the deformations are persistent problems in undeveloped and developing country roads due to low-cost road policy (Ben-Edigbe 2010). However, the situation is not only seen in undeveloped or developing countries, which have poor road surface condition problems. In addition, developed countries have road surface problems resulting from work zones, climatic conditions, and excessive loads etc. In order to detect and fix these mentioned problems, many countries have been working to monitor these deformations by utilizing special devices and techniques (TRB 2004; Oloufa et al. 2004; Lee, Kim 2005; Battiato et al. 2006; Dell'Acqua et al. 2011; Strazdins et al. 2011; Žilionienè et al. 2013).

Corresponding author: Metin Mutlu Aydin

E-mail: metinmutluaydin@gmail.com 
Surface deformations have significant impact on vehicle speed and traffic flow conditions. They limit driving properties such as driving comfort, vehicle control etc. However, they cause an increase on the cost of operating of vehicles as well as on, maintenance and pavement management costs. Additionally, not only they cause traffic congestion problems and accidents; but also they cause slower movement speeds, longer travel times, longer queuing and severe discomfort problems (Ben-Edigbe 2010). Some earlier results show that deformations have great effect on the maximum traffic flow (capacity) of uninterrupted road link sections (BenEdigbe, Ferguson 2005). Ben-Edigbe et al. (2011) tried to explore trapezoidal flow rate contractions resulting from surface deformations. They found that there is a significant variation in vehicle speed between 'with' and 'without' deformation sections. Ben-Edigbe and Ferguson (2005) obtained that a decrease in capacity caused by the pavement surface deformations is about $30 \%$ and average speed reduction is about $40 \mathrm{~km} / \mathrm{h}$. Ben-Edigbe (2010) has indicated that adverse conditions have significant impact on level of service of a road. He concluded that the deformations would result a significant reduction in speed by up to $50 \%$ and in traffic flow by up to $20 \%$. Ben-Edigbe (2005) measured decrease in capacity of road by $30 \%$ with an average speed reduction of about $50 \%(20 \mathrm{~km} / \mathrm{h})$. However, the results of some studies exhibited that potholes on pavement surfaces may reduce speeds average $6 \mathrm{~km} / \mathrm{h}$ according to Transportation Research Laboratory (TRL), Crowthorne, England (Ross et al. 1991).

Various traffic flow theories investigated longitudinal and lateral behaviours of vehicles on straight sections of roads. These flow theories experimented longitudinal flow movements, and that they exhibit significant role in directly or indirectly defining lateral positions of vehicles (Aydın 2013). In lane-based car following theory, vehicles continue their movement centering the lanes. Each vehicle is directly influenced by the movement of vehicle in front and at the back. Based on this theory, lateral positions of vehicles on lanes are expected to exhibit normal distribution (Gunay 2001, 2008, 2009; Timm, Priest 2005; Gunay, Woodward 2007; Yousif et al. 2013). However, in some unexpected traffic situations, lane-based driving discipline is weak. Therefore, lateral positions of vehicles on lanes may not correspond to normal distribution due to external factors (Khan, Maini 1999, Gunay 2004). It is also possible to see different lane utilization behaviours of drivers resulting from low lane visibility, inadequate lane width and low lane-based driving discipline of drivers (Gunay 2008).

Previous studies regarding the investigation of the effect of road surface deformations have been very limited. They generally focused on examining the negative effects of road surface deformations on traffic flow, road safety, pavement management, level of service etc. (Ross et al. 1991; Ben-Edigbe 2005; Ben-Edigbe, Ferguson 2005; Ben-Edigbe 2010; Strazdins et al. 2011). However, many researches has been conducted on lane utilization (Gunay 2001, 2009; Timm, Priest 2005; Gunay, Wood- ward 2007; Tanyel et al. 2013; Yousif et al. 2013). However, these studies did not combine the negative effect of surface deformations on lateral lane utilization and longitudinal driving behaviour. The objective of this study is to determine the negative effect of deformations on lateral lane utilization and longitudinal driving behaviours by considering the various effective parameters.

\section{Data Collection and Methodology}

In this study, data were collected based on the belonging to lateral positions of vehicles traveling on lanes throughout four different deformation zones (Deformation Zone 1, 2, 3 and 4) on the main arterial roads of Tinaztepe Campus (Izmir, Turkey) (Fig. 1). Deformation Zones 1, 2 and 3 (DZ-1, DZ-2 and DZ-3) are formed by heavy vehicles and environmental effects. However, Deformation Zone 4 (DZ-4) is formed by the removal of certain part of a speed bump. It was removed to decrease deformation impact on the right lane after some time to increase the value of traffic flow. The choice of Tinaztepe campus is based on the following factors:

- availability of various flow densities on main arterials;

- heavy vehicle such as bus, truck, etc. effects can be seen on pavement surface;

- availability of various type of deformations and speed bump on arterials;

- parking ban on main arterials of campus;

- uninterrupted flow conditions resulting from signals, intersection, etc.;

- availability to take video recordings from high locations to use screen scaling method on arterials;

- visible road surface signs (available lane separation).

Road surface deformations seen on the same position but different places on lanes were categorized in the same deformation zone. Geometrical features and structural properties of deformation zones are presented in Table 1.

All observations were made for different traffic flow conditions, dates and times by using video camera recordings. Cameras were placed at high locations where

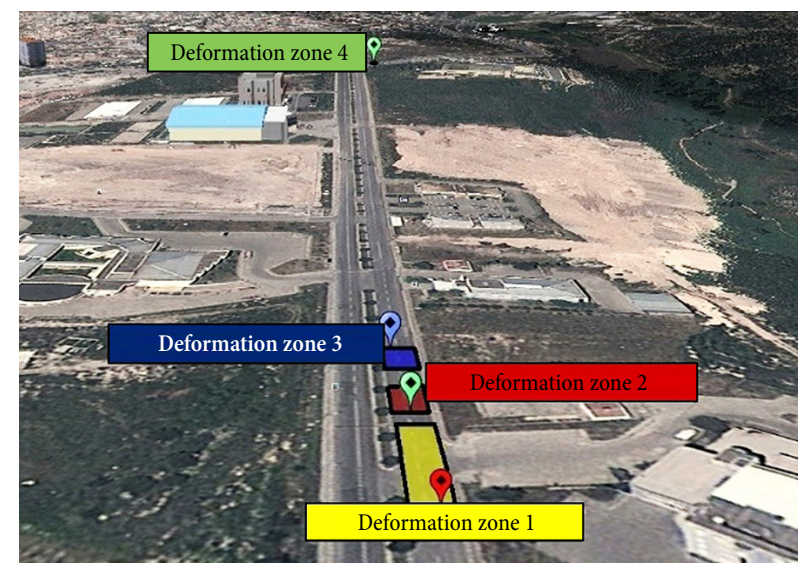

Fig. 1. Positions of selected deformation zones on examined road surface 
Table 1. Deformation zones and their geometrical and structural properties.

\begin{tabular}{|c|c|c|c|c|c|c|l|}
\hline $\begin{array}{c}\text { Deformation } \\
\text { zone }\end{array}$ & $\begin{array}{c}\text { Deformation } \\
\text { point }\end{array}$ & $\begin{array}{c}\text { Width, } \\
W_{d}[\mathrm{~m}]\end{array}$ & $\begin{array}{c}\text { Length, } \\
L_{d}[\mathrm{~m}]\end{array}$ & $\begin{array}{c}\text { Depth/Height, } \\
D_{d} / H_{d}[\mathrm{~cm}]\end{array}$ & $\begin{array}{c}\text { Road width, } \\
B_{r}[\mathrm{~m}]\end{array}$ & $\begin{array}{c}\text { Position on road } \\
\text { surface, } P_{d}[\mathrm{~m}]\end{array}$ & \multicolumn{1}{|c|}{ Deformation type, $S_{d}$} \\
\hline \multirow{2}{*}{1} & $\mathrm{~A}$ & 2 & 1.8 & 6.5 & 9.6 & $(3.6-5.6)$ & $\begin{array}{l}\text { deflection and alligator } \\
\text { cracking }\end{array}$ \\
\cline { 2 - 9 } & $\mathrm{B}$ & 1.6 & 2 & 6.5 & 9.6 & $(3.9-5.5)$ & $\begin{array}{l}\text { deflection and alligator } \\
\text { cracking }\end{array}$ \\
\hline \multirow{2}{*}{2} & $\mathrm{~A}$ & 1.45 & 2 & 6 & 9.6 & $(1-2.45)$ & $\begin{array}{l}\text { deflection and alligator } \\
\text { cracking }\end{array}$ \\
\cline { 2 - 9 } & $\mathrm{B}$ & 2 & 1.5 & 6.7 & 9.6 & $(1-3)$ & $\begin{array}{l}\text { stripping. deflection and } \\
\text { alligator cracking }\end{array}$ \\
\hline \multirow{2}{*}{3} & $\mathrm{~A}$ & 0.97 & 2.57 & 3.5 & 9.6 & $(0.9-1.87)$ & ravelling and weathering \\
\hline 4 & A & 3 & 3.1 & 9 & 9.6 & $(0-3)$ & $\begin{array}{l}\text { high severity alligator } \\
\text { cracking and ravelling }\end{array}$ \\
\hline
\end{tabular}

drivers could not notice. In this study 40,45 , and $30 \mathrm{~min}$ data sets were obtained from DZ-1, DZ-2; DZ-3 and DZ-4 respectively. All data were collected throughout the weekdays under dry and open weather conditions. Collected video recordings were evaluated by using Screen Ruler Software (MB-Ruler@) analysis programs. Position of moving vehicles on deformation zones were determined and measured by using screen scaling method in MB-Ruler@ (Fig. 2). In this method, road surfaces were divided into $20 \mathrm{~cm}$ distances on the screen, and position data belonging to right and left wheels of each vehicle were obtained by using the Eq. (1):

$$
T=\frac{\sum_{i=1}^{n} l_{i}}{N} \cdot m_{n},
$$

where: $T$ - position of right and left wheels of the vehicle on road surface $[\mathrm{cm}] ; l_{i}$ - lane width $[\mathrm{cm}] ; \mathrm{N}$ - selected constant range distance for scaling purposes $[\mathrm{cm}] ; m_{n}-$ beginning from the shoulder, the range where right or left wheel of vehicle takes place.

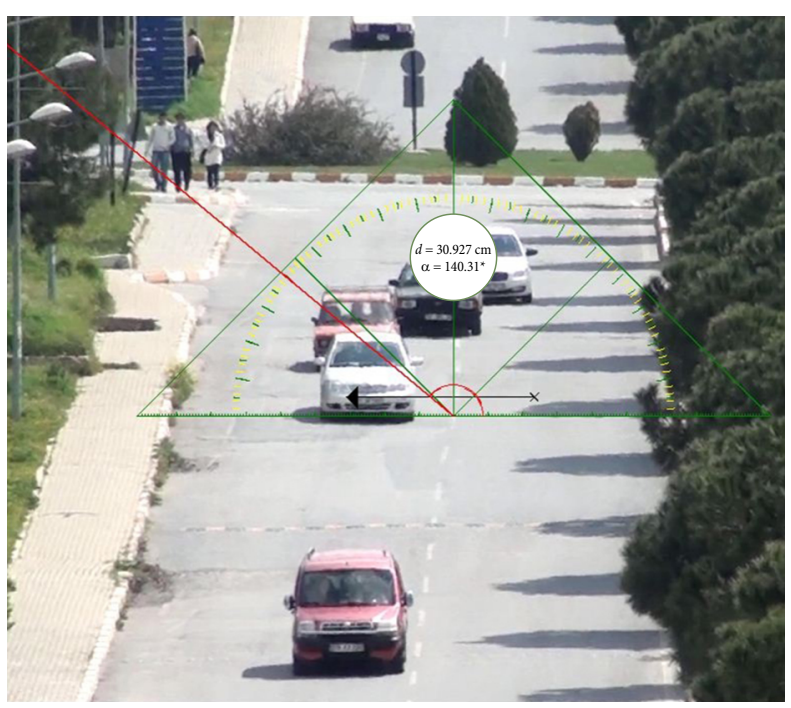

Fig. 2. Application of screen scaling technique
Right and left wheel positions of 697 vehicles were successfully observed. However, wheel positions of 170 vehicles were not collected because of leading vehicles' positions. Using obtained right and left wheel lateral positions of vehicles, average axle lengths of vehicles traveling on lanes were determined by using Eq. (2):

$$
\bar{L}_{n}=\frac{\sum_{i=1}^{n}\left(m_{l_{i}}-m_{r_{i}}\right)}{K},
$$

where: $\bar{L}_{n}$ - average vehicle axle length $[\mathrm{cm}] ; m_{l_{i}}$ - beginning from the shoulder, the range where left wheel of vehicle takes place $[\mathrm{cm}] ; m_{r_{i}}$ - beginning from the shoulder, the range where right wheel of vehicle takes place $[\mathrm{m}] ; K$ - total number of observed vehicles.

Lateral positions and average axle lengths of vehicles based on vehicle types and lane width on road were used in analyses. All observed and unobserved vehicles with axle lengths are presented in Table 2.

To determine longitudinal lane utilization and driving behaviour, 5 different drivers (4 male and 1 female) were selected. Typical GPS devices were installed into the vehicles that they are using the same route every day. Speed profile, acceleration/deceleration and delay times of the vehicles resulted from the road surface deformations were obtained by the way of GPS device, which has less than $1 \mathrm{sec}$. delay error. The collected data includes 18 lap movements of 5 different vehicles on about $2 \mathrm{~km}$ road (Fig. 3).

\section{Results and Evaluations}

\subsection{Lateral Lane Utilization}

Following the determination of the lateral positions of vehicles for each deformation zone, data belonging to lateral lane utilization of vehicles traveling through deformation zones were examined. Frequency distributions for lateral lane utilization of right and left wheels were obtained for each deformation zone. By using the obtained frequency distributions, statistical analysis was performed to determine lane utilization behaviour of vehicles on deformed or non-deformed road sections. Considering the $5 \%$ level of probability with a minimum 
Table 2. Characteristics of data used in analyses

\begin{tabular}{|c|c|c|c|c|c|c|c|c|}
\hline \multirow{2}{*}{$\begin{array}{l}\text { Deformation } \\
\text { zone }\end{array}$} & \multirow{2}{*}{ Lane } & \multirow{2}{*}{$\begin{array}{l}\text { Lane width } \\
{[\mathrm{cm}]}\end{array}$} & \multirow{2}{*}{$\begin{array}{l}\text { Average axle } \\
\text { width }[\mathrm{cm}]\end{array}$} & \multicolumn{4}{|c|}{ Number and type of observed vehicles [\%] } & \multirow{2}{*}{ Unobserved vehicle } \\
\hline & & & & Passenger car & Minibus & Bus & Truck & \\
\hline \multirow{2}{*}{1} & right & 460 & 177.51 & $71 /(10.2)$ & $7 /(1)$ & $1 /(0.14)$ & $0 /(0)$ & $17 /(22)$ \\
\hline & left & 500 & 178.55 & $93 /(13.3)$ & $5 /(0.7)$ & $0 /(0)$ & $0 /(0)$ & $18 /(18)$ \\
\hline \multirow{2}{*}{2} & right & 460 & 181.36 & $65 /(9.3)$ & $4 /(0.5)$ & $2 /(0.3)$ & $0 /(0)$ & $4 /(6)$ \\
\hline & left & 500 & 177.30 & $104 /(14.9)$ & $8 /(1.1)$ & $0 /(0)$ & $0 /(0)$ & $9 /(8)$ \\
\hline \multirow{2}{*}{3} & right & 460 & 174.63 & $48 /(6.9)$ & $4 /(0.5)$ & $1 /(0.14)$ & $0 /(0)$ & $5 /(9)$ \\
\hline & left & 500 & 173.96 & $79 /(11.3)$ & $4 /(0.5)$ & $0 /(0)$ & $1 /(0.14)$ & $18 /(21)$ \\
\hline \multirow{2}{*}{4} & right & 460 & 161.18 & $145 /(20.8)$ & $5 /(0.7)$ & $4 /(0.5)$ & $0 /(0)$ & $86 /(56)$ \\
\hline & left & 500 & 167.60 & $44 /(6.3)$ & $1 /(0.14)$ & $1 /(0.14)$ & $0 /(0)$ & $13 /(28)$ \\
\hline
\end{tabular}

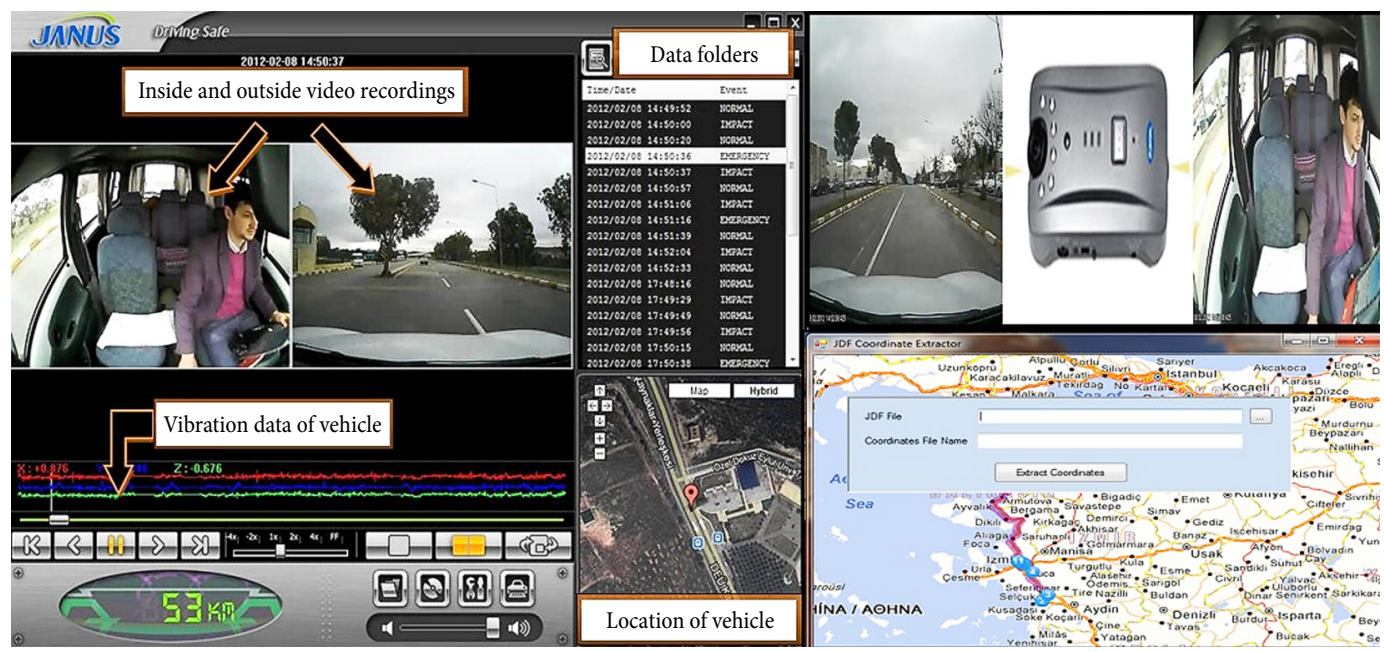

Fig. 3. Collection of speed and location data using GPS devices

class size of 5 on lateral positions, chi-square $\left(\chi^{2}\right)$ goodness of fit test was conducted to compare with normal distribution on deformation zones. After determination of frequency distributions of lateral lane utilizations, obtained distributions were compared with normal distribution to see the effect of deformations (Table 3).

As seen from Table 3, probability of excessing frequency distributions of wheel positions for DZ-2 left lane left wheel, DZ-3 right lane right wheel, DZ-4 right lane right and left wheels, and left lane left wheel are not fit to normal distribution. Also, axle lengths of vehicles have been measured and the axle lengths were then averaged. For each deformation zone on right/left lanes, average axle lengths $\left(\bar{L}_{n}\right)$ of vehicles were obtained. Assuming that vehicles would continue to travel fully centring the lanes, the axle lengths were centred on the lanes and expected positions of vehicles were obtained. Based on the observed positions of vehicles, comparison of expected positions to normal distribution was examined and the results were presented in Table 4.

It can be seen from the comparison results of expected positions to normal distribution according to observed positions, none of right and left wheel positions fit to normal distribution. Results showed that there is a deviation from their expected positions of DZ-1 left lane right and left wheels, and DZ-2 left lane right and left wheels.
As an example, the relation between expected position and observed position for DZ-1 right lane left wheel is presented in Fig. 4 for normal distribution results given in Table 4. As can be seen from the Fig. 4, there are great differences between expected and observed position of vehicle. The normal distribution for the observed position on the figure is clearly skewed to the left. Peak point for frequency distribution of vehicles is expected around $300 \mathrm{~cm}$. However, it is obtained around $380 \mathrm{~cm}$ due to this skewness.

Lateral axle positions of vehicles on DZ-1 are presented in Fig. 5. The figure indicates that the effect of deformation is between 420 and $470 \mathrm{~cm}$ of the road. Vehicles are traveling either by centring over deformation zone or from right/left of deformation zone.

Using the histogram in Fig. 5, right and left wheel frequency distributions of vehicles for both lanes are computed to fit the normal distribution. It can be concluded that DZ-1 does not have significant impact on lateral lane utilization of vehicles. The most significant factor on this result is the size and depth of deformation zone. From the measurements, deepest part was found $6.5 \mathrm{~cm}$ on DZ-1. However, it is observed that this depth does not continue over all deformation zone. Therefore, it is noticed that this depth does not prevent vehicles from traveling on this point. 
Table 3. The result of goodness of fit tests for the observed lateral vehicle positions

\begin{tabular}{|c|c|c|c|c|c|c|}
\hline \multirow{2}{*}{$\begin{array}{l}\text { Deformation } \\
\text { zone }\end{array}$} & \multirow{2}{*}{ Lane } & \multirow{2}{*}{$\begin{array}{c}\text { Wheel } \\
\text { position } P_{w}\end{array}$} & \multirow{2}{*}{$\begin{array}{l}\text { Degree of } \\
\text { freedom }\end{array}$} & \multicolumn{3}{|c|}{ The situation when expected vehicle position is accepted in the centre of lanes } \\
\hline & & & & Chi-square $\left(\chi^{2}\right)$ calculated & Chi-square $\left(\chi^{2}\right)$ from table & Normal distribution fit? \\
\hline \multirow{4}{*}{1} & \multirow{2}{*}{ right } & right & 29 & 21.92 & 42.56 & yes \\
\hline & & left & 29 & 22.46 & 42.56 & yes \\
\hline & \multirow{2}{*}{ left } & right & 30 & 39.87 & 43.77 & yes \\
\hline & & left & 30 & 28.16 & 43.77 & yes \\
\hline \multirow{4}{*}{2} & \multirow{2}{*}{ right } & right & 29 & 32.47 & 42.56 & yes \\
\hline & & left & 29 & 20.77 & 42.56 & yes \\
\hline & \multirow{2}{*}{ left } & right & 30 & 46.14 & 43.77 & no \\
\hline & & left & 30 & 84.23 & 43.77 & no \\
\hline \multirow{4}{*}{3} & \multirow{2}{*}{ right } & right & 29 & 46.19 & 42.56 & no \\
\hline & & left & 29 & 37.58 & 42.56 & yes \\
\hline & \multirow{2}{*}{ left } & right & 30 & 34.33 & 43.77 & yes \\
\hline & & left & 30 & 28.54 & 43.77 & yes \\
\hline \multirow{4}{*}{4} & \multirow{2}{*}{ right } & right & 29 & 229.44 & 42.56 & no \\
\hline & & left & 29 & 353.11 & 42.56 & no \\
\hline & \multirow{2}{*}{ left } & right & 30 & 37.48 & 43.77 & yes \\
\hline & & left & 30 & 50.63 & 43.77 & no \\
\hline
\end{tabular}

Table 4. The result of goodness of fit for the expected lateral vehicle position

\begin{tabular}{|c|c|c|c|c|c|c|}
\hline \multirow{2}{*}{$\begin{array}{c}\text { Deformation } \\
\text { zone }\end{array}$} & \multirow{2}{*}{ Lane } & \multirow{2}{*}{$\begin{array}{c}\text { Wheel } \\
\text { position } P_{w}\end{array}$} & \multirow{2}{*}{$\begin{array}{l}\text { Degree of } \\
\text { freedom }\end{array}$} & \multicolumn{3}{|c|}{ The situation when expected vehicle position is accepted in the centre of lanes } \\
\hline & & & & Chi-square $\left(\chi^{2}\right)$ calculated & Chi-square $\left(\chi^{2}\right)$ from table & Normal distribution fit? \\
\hline \multirow{4}{*}{1} & \multirow{2}{*}{ right } & right & 29 & 135.40 & 42.56 & no \\
\hline & & left & 29 & 114.55 & 42.56 & no \\
\hline & \multirow{2}{*}{ left } & right & 30 & 47667.75 & 43.77 & no \\
\hline & & left & 30 & 14293.89 & 43.77 & no \\
\hline \multirow{4}{*}{2} & \multirow{2}{*}{ right } & right & 29 & 112.75 & 42.56 & no \\
\hline & & left & 29 & 99.03 & 42.56 & no \\
\hline & \multirow{2}{*}{ left } & right & 30 & 17496.98 & 43.77 & no \\
\hline & & left & 30 & 27342.88 & 43.77 & no \\
\hline \multirow{4}{*}{3} & \multirow{2}{*}{ right } & right & 29 & 67.27 & 42.56 & no \\
\hline & & left & 29 & 69.65 & 42.56 & no \\
\hline & \multirow{2}{*}{ left } & right & 30 & 207.91 & 43.77 & no \\
\hline & & left & 30 & 174.47 & 43.77 & no \\
\hline \multirow{4}{*}{4} & \multirow{2}{*}{ right } & right & 29 & 506.16 & 42.56 & no \\
\hline & & left & 29 & 834.77 & 42.56 & no \\
\hline & \multirow{2}{*}{ left } & right & 30 & 320.44 & 43.77 & no \\
\hline & & left & 30 & 752.71 & 43.77 & no \\
\hline
\end{tabular}

Frequency distributions of lateral positions on lanes for vehicles traveling through DZ-2 is seen in Fig. 6. Fig. 6 depicts that there is no vehicle travels through $160-180 \mathrm{~cm}$ range of right lane. As stated previously, the most significant factor here is the depth and magnitude of deformation. Depth for deformation zone in Fig. 6 is measured as $6.7 \mathrm{~cm}$. However, current depth extends laterally for $60 \mathrm{~cm}$. Based on the result, horizontal magnitude of deformation zone, horizontal and vertical magnitude of depth should be taken into the consideration in analysis.

As can be seen from Fig. 6, frequency distributions of right and left wheels of vehicles DZ-2 fit normal distribution for both wheels by using the right lane on DZ-2. However, frequency distributions of right and left wheels of vehicles do not fit normal distribution by using the left lane. Because of the moving vehicles on right lane affect the moving vehicles on left lane. 
Frequency distributions of lateral positions of vehicles traveling through DZ-3 are shown in Fig. 7. In $\mathrm{DZ}-3$, deformation is on the $0-170 \mathrm{~cm}$ range of right lane. However, it does not seriously affect lateral lane utilization. Depth on deformation is measured as $9 \mathrm{~cm}$ and width of current depth is determined around $30 \mathrm{~cm}$. It is also observed that vehicles traveling on DZ-3 were only a few. Reconsidering the video records, it is seen

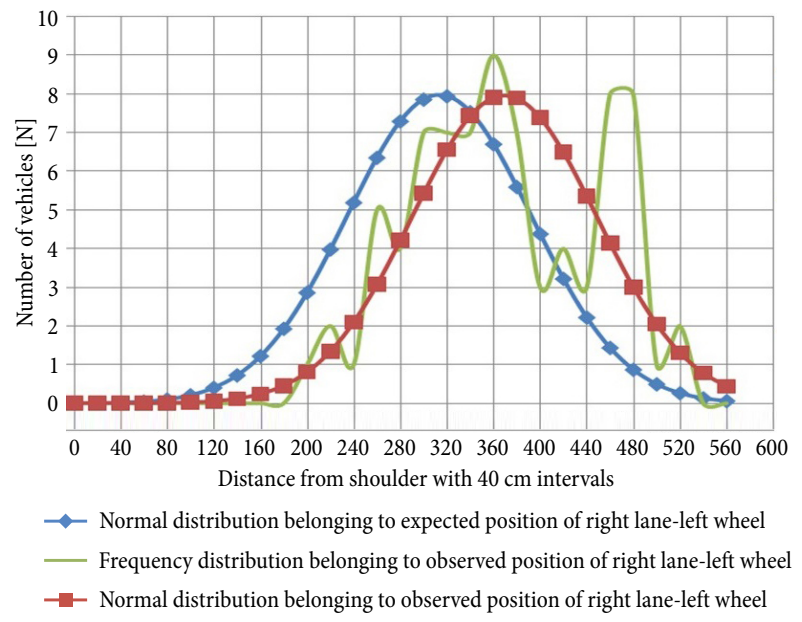

Fig. 4. Frequency distribution relation between expected and observed position of right lane left wheel for DZ-1 that heavy vehicles are less affected from the deformation impact. This irregular right wheel frequency distribution on 1-170 cm range of right lane does not fit normal distribution. On the other hand, it is seen that observed left wheel frequency distribution of vehicles on right lane fits the normal distribution.

Lateral distributions of vehicles traveling through DZ-4 (road hump) are shown in lanes in Fig. 8. The position and lateral width of deformation located on DZ-4 are observed to be quite significant. The deformation on DZ-4 consists of two parts. First of these is the part located on $190-250 \mathrm{~cm}$ and the second pert is on $400-$ $900 \mathrm{~cm}$ range. In addition, hump height of deformation was measured as $3.5 \mathrm{~cm}$.

As seen from Fig. 8, due to continuous deformation along the left lane, vehicles preferred to move on the right lane. The impact of the height along the all left lane and a part of the right lane affect drivers to choose more comfortable and less harmful lane to consider mechanical parts of the vehicle. As a result, right and left wheel frequency distribution of vehicles traveling on right lane does not fit normal distribution. In addition, the frequency distribution of right wheels of vehicles traveling on the left lane is observed to fit the normal distribution. However, left wheel frequency distribution does not fit normal distribution since no vehicle travels on $910-960 \mathrm{~cm}$ range of the road.

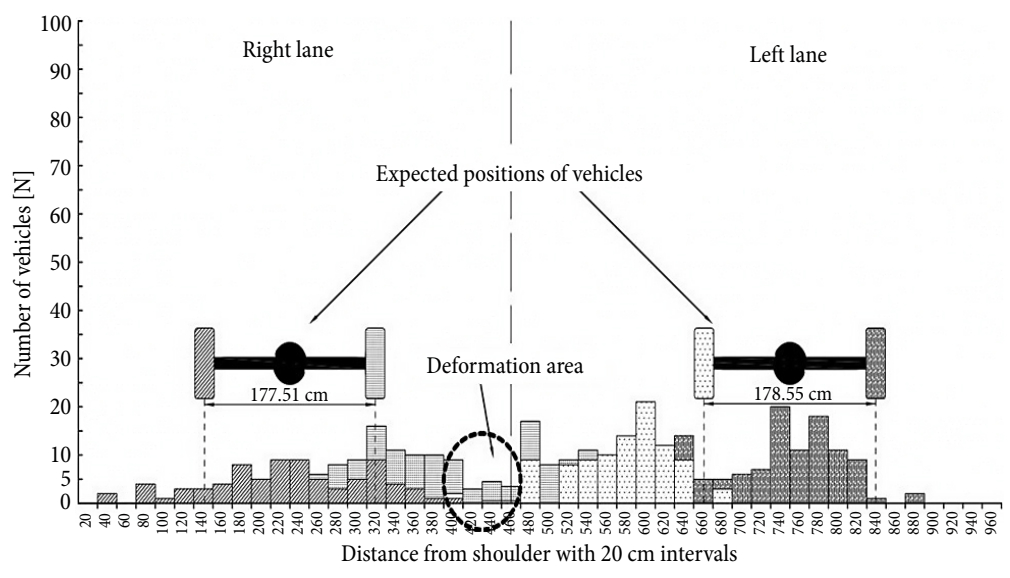

Fig. 5. Frequency distributions belonging to lateral lane utilization of vehicles on DZ-1

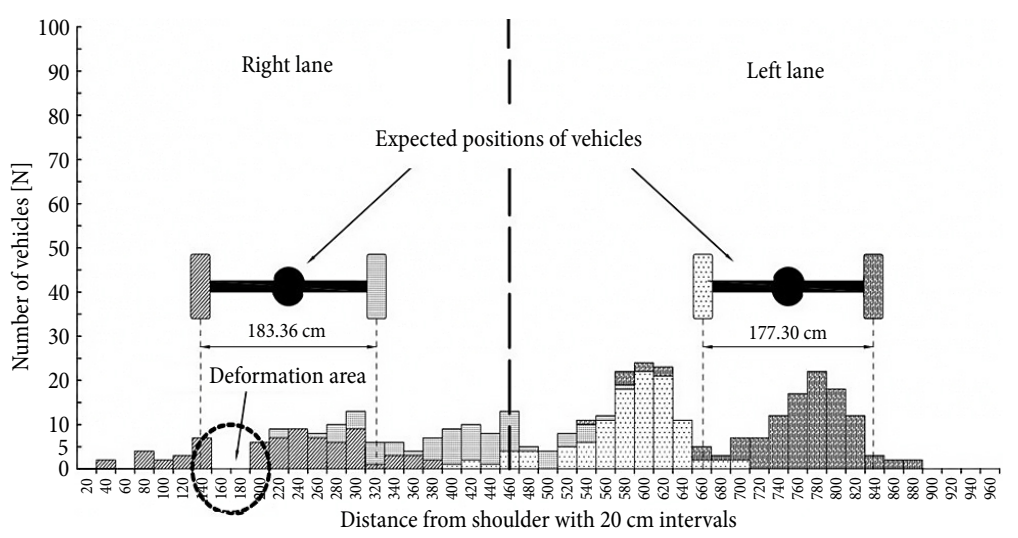

Fig. 6. Frequency distributions belonging to lateral lane utilization of vehicles on DZ-2 


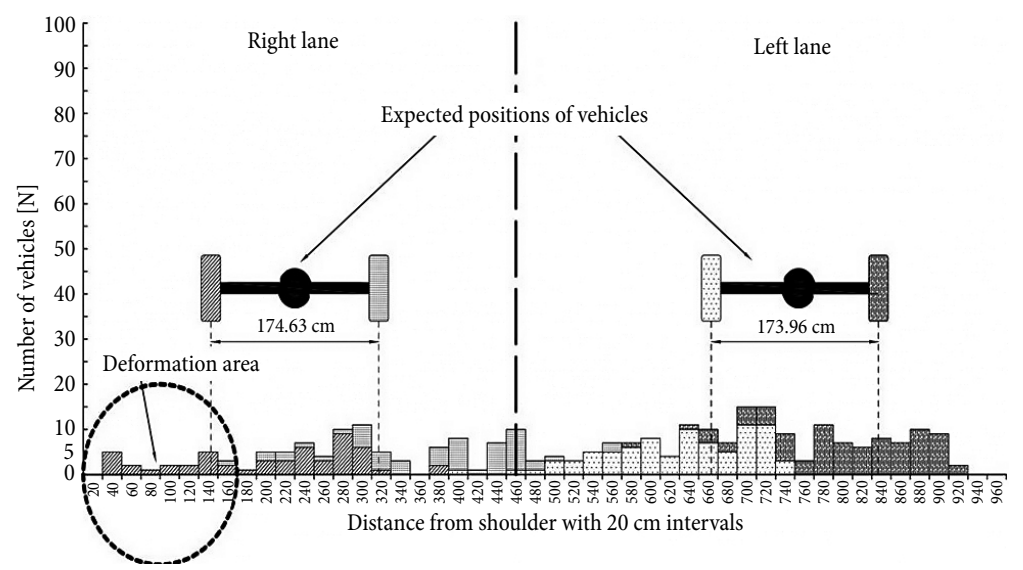

Fig. 7. Frequency distributions belonging to lateral lane utilization of vehicles on DZ-3

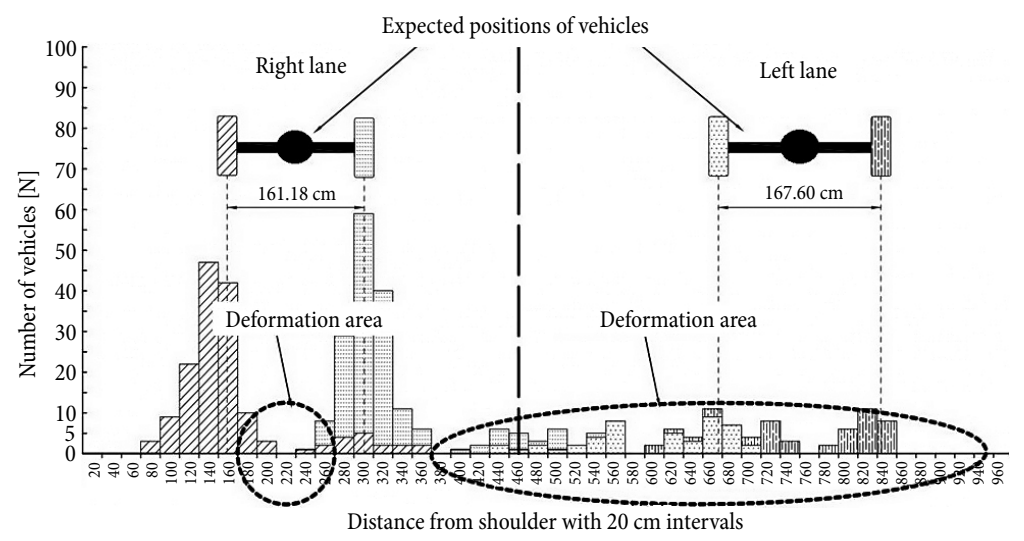

Fig. 8. Frequency distributions belonging to lateral lane utilization of vehicles on DZ-4

\subsection{Longitudinal Lane Utilization}

Standard deviations of maximum, minimum and average speed values for four different deformation zone and five different drivers were presented in Table 5. It can be seen from Table 5 that, vehicles are willing to decrease their speeds or change their lanes to avoid from deformation effect. In addition, standard deviation values of the speeds were found to be significantly higher considering the non-deformed section of the road. This indicates that vehicles travel more stable in non-deformed zones with respect to deformed zones. While the data was investigated considering five different driver types, it was found that the speed values and the corresponding standard deviations obviously different from each other. From the obtained results, standard deviation of the speed for 1st driver was 11.06 on DZ-3, 11.67 for 2nd driver on DZ-2, 2.79 for 3rd driver on DZ-2 and DZ-3, 1.68 for 4th driver on DZ-1 and 2.7 for 5th driver on DZ-5. These results indicate that DZ-2 is subject to the greatest speed variations among all deformation zones. In addition, the 2 nd driver has the highest standard deviation of the speed, and it shows that 2 nd driver has an aggressive driver characteristics. However, it can be seen from Table 5 DZ-2 has more effect on speed differences for five drivers.

The acceleration, deceleration and delay values were shown in Table 6 for five different driver charac- teristics on deformation zones. Based on the delay results in Table 6,5th driver has maximum delay on five deformation zones. These results indicate that 5 th driver felt the highest deformation effect among all deformation zones. It can be seen from Table 5 and 6,2 nd driver has the highest standard deviation of the speed and 5th driver has the maximum delay. It means that 2 nd driver has an aggressive and 5th driver is quite careful driver characteristics. Hence, it can be said that deformation zones have different effect on drivers.

The speed-position relationship for five different drivers on deformed road (DZ 1-4) is shown in Fig. 9.

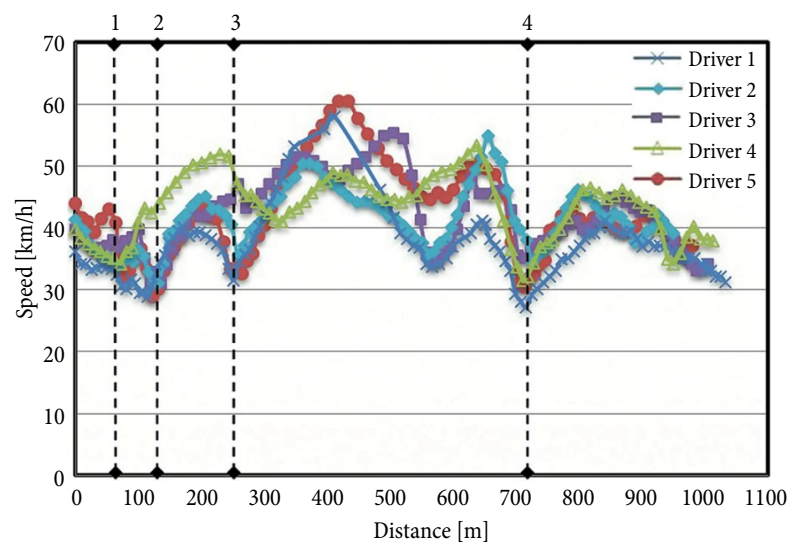

Fig. 9. Speed profile of five drivers on deformed road 
Table 5. Average standard deviations of speeds for five different drivers on deformed zones

\begin{tabular}{|c|c|c|c|c|c|c|c|c|c|c|c|c|c|c|c|c|c|c|c|c|c|}
\hline \multirow{2}{*}{$\begin{array}{l}\text { Deforma- } \\
\text { tion zone }\end{array}$} & \multirow{2}{*}{ Location } & \multicolumn{4}{|c|}{ Driver 1} & \multicolumn{4}{|c|}{ Driver 2} & \multicolumn{4}{|c|}{ Driver 3} & \multicolumn{4}{|c|}{ Driver 4} & \multicolumn{4}{|c|}{ Driver 5} \\
\hline & & $v_{\max }$ & $v_{\min }$ & $v_{\text {avg }}$ & $\sigma$ & $v_{\max }$ & $v_{\min }$ & $v_{\text {avg }}$ & $\sigma$ & $v_{\max }$ & $v_{\text {min }}$ & $v_{\text {avg }}$ & $\sigma$ & $v_{\max }$ & $v_{\min }$ & $v_{\text {avg }}$ & $\sigma$ & $v_{\max } \mid$ & $v_{\min }$ & $v_{\text {avg }}$ & $\sigma$ \\
\hline \multirow{3}{*}{1} & before & 44 & 27 & 34 & 5.15 & 49 & 30 & 38 & 4.83 & 40 & 35 & 38 & 2.51 & 39 & 36 & 37 & 1.09 & 45 & 36 & 41 & 4.23 \\
\hline & $\begin{array}{l}\text { defor- } \\
\text { mation } \\
\text { zone }\end{array}$ & 48 & 23 & 32 & 7.51 & 47 & 21 & 34 & 7.71 & 39 & 36 & 37 & 1.08 & 37 & 32 & 34 & 1.68 & 32 & 27 & 30 & 1.84 \\
\hline & after & 45 & 26 & 31 & 6.26 & 51 & 24 & 35 & 7.27 & 41 & 36 & 39 & 2.62 & 40 & 36 & 37 & 1.91 & 37 & 33 & 34 & 2.65 \\
\hline \multirow{3}{*}{2} & before & 46 & 24 & 30 & 6.95 & 51 & 28 & 35 & 7.02 & 35 & 31 & 33 & 1.97 & 45 & 39 & 42 & 2.56 & 38 & 32 & 35 & 3.01 \\
\hline & \begin{tabular}{|l|} 
defor- \\
mation \\
zone \\
\end{tabular} & 47 & 17 & 29 & 9.51 & 49 & 17 & 31 & 11.67 & 36 & 29 & 33 & 2.79 & 45 & 42 & 44 & 1.55 & 29 & 23 & 25 & 2.44 \\
\hline & after & 53 & 25 & 36 & 7.7 & 55 & 28 & 40 & 7.77 & 42 & 34 & 37 & 4.03 & 51 & 42 & 47 & 4.56 & 45 & 30 & 37 & 6.15 \\
\hline \multirow{3}{*}{3} & before & 54 & 23 & 38 & 8.19 & 58 & 31 & 42 & 7.45 & 46 & 40 & 43 & 2.85 & 53 & 48 & 51 & 2.26 & 45 & 37 & 41 & 4.06 \\
\hline & $\begin{array}{l}\text { defor- } \\
\text { mation } \\
\text { zone }\end{array}$ & 51 & 15 & 33 & 11.06 & 55 & 15 & 36 & 9.6 & 51 & 44 & 47 & 2.79 & 49 & 44 & 46 & 1.6 & 34 & 32 & 33 & 1.09 \\
\hline & after & 62 & 30 & 42 & 8.27 & 58 & 28 & 44 & 7.56 & 51 & 42 & 48 & 4.52 & 50 & 40 & 45 & 4.95 & 61 & 32 & 47 & 7.75 \\
\hline \multirow{3}{*}{4} & before & 64 & 30 & 52 & 6.45 & 54 & 38 & 45 & 4.01 & 52 & 42 & 48 & 3.96 & 48 & 38 & 42 & 4.08 & 56 & 35 & 42 & 6.72 \\
\hline & $\begin{array}{l}\text { defor- } \\
\text { mation } \\
\text { zone }\end{array}$ & 57 & 21 & 44 & 8.8 & 47 & 24 & 38 & 6.32 & 43 & 40 & 41 & 1.09 & 40 & 36 & 38 & 1.52 & 31 & 24 & 29 & 2.7 \\
\hline & after & 56 & 33 & 47 & 5.87 & 57 & 32 & 44 & 4.87 & 48 & 39 & 44 & 3.76 & 43 & 36 & 39 & 2.98 & 40 & 26 & 34 & 5.39 \\
\hline
\end{tabular}

Notes: $v_{\max }-$ maximum speed on deformation zone $[\mathrm{km} / \mathrm{h}] ; v_{\min }-$ minimum speed on deformation zone $[\mathrm{km} / \mathrm{h}] ; v_{\text {avg }}-$ average speed on deformation zone $[\mathrm{km} / \mathrm{h}] ; \sigma-$ standard deviations of the speeds.

Table 6. Acceleration/deceleration rate and delay values of five different drivers before and after deformed zones

\begin{tabular}{|c|c|c|c|c|c|c|c|c|c|c|c|c|c|c|c|c|}
\hline \multirow{2}{*}{$\begin{array}{l}\text { Deforma- } \\
\text { tion zone }\end{array}$} & \multirow{2}{*}{ Location } & \multicolumn{3}{|c|}{ Driver 1} & \multicolumn{3}{|c|}{ Driver 2} & \multicolumn{3}{|c|}{ Driver 3} & \multicolumn{3}{|c|}{ Driver 4} & \multicolumn{3}{|c|}{ Driver 5} \\
\hline & & $a(+)$ & $a(-)$ & $T_{\text {delay }}$ & $a(+)$ & $a(-)$ & $T_{\text {delay }}$ & $a(+)$ & $a(-)$ & $T_{\text {delay }}$ & $a(+)$ & $a(-)$ & $T_{\text {delay }}$ & $a(+)$ & $a(-)$ & $T_{\text {delay }}$ \\
\hline \multirow{2}{*}{1} & before & - & 0.622 & \multirow{2}{*}{6.21} & - & .763 & \multirow{2}{*}{13.49} & - & 0.242 & \multirow{2}{*}{2.80} & - & 0.438 & \multirow{2}{*}{11.03} & - & 1.233 & \multirow{2}{*}{32.77} \\
\hline & after & 0.138 & - & & 0.659 & - & & - & 0.926 & & 2.355 & - & & 1.828 & - & \\
\hline \multirow{2}{*}{2} & before & - & 0.161 & \multirow{2}{*}{20.62} & - & 1.411 & \multirow{2}{*}{23.19} & - & 1.412 & \multirow{2}{*}{14.91} & 1.080 & - & \multirow{2}{*}{12.62} & - & 2.316 & \multirow{2}{*}{58.88} \\
\hline & after & 0.992 & - & & 1.277 & - & & 1.710 & - & & 1.319 & - & & 1.841 & - & \\
\hline \multirow{2}{*}{3} & before & - & 0.896 & \multirow{2}{*}{2.93} & - & 1.263 & \multirow{2}{*}{8.48} & 0.239 & - & \multirow{2}{*}{19.32} & - & 1.070 & \multirow{2}{*}{17.87} & - & 1.990 & \multirow{2}{*}{20.68} \\
\hline & after & 1.705 & - & & 1.305 & - & & 0.963 & - & & 0.212 & - & & 1.677 & - & \\
\hline \multirow{2}{*}{4} & before & - & 1.364 & \multirow{2}{*}{13.50} & - & 1.090 & \multirow{2}{*}{24.83} & - & 0.917 & \multirow{2}{*}{19.16} & - & 0.580 & \multirow{2}{*}{4.03} & - & 1.969 & \multirow{2}{*}{40.4} \\
\hline & after & 0.652 & - & & 0.974 & - & & 0.521 & - & & 0.410 & - & & 0.967 & - & \\
\hline
\end{tabular}

Notes: $a(+)$ - acceleration values of vehicles after deformed zone $[\mathrm{km} / \mathrm{h} / \mathrm{sec}] ; a(-)-$ deceleration of vehicles resulting from deformation effect $[\mathrm{km} / \mathrm{h} / \mathrm{sec}] ; T_{\text {delay }}$ - delay values on examined road length resulting deformation zone [sec].

As can be seen in Fig. 9 deformations cause the drops of the vehicles speeds for all deformation zones. Additionally, the peak speeds of the vehicles are located in the same place but yield different values between the deformation zones. The most significant factor is the characteristics of the driver.

\section{Conclusions and Suggestions}

In the present study, lateral lane utilization and longitudinal driving behaviours of vehicles on a two-lane road with surface deformations were investigated. Lateral lane utilization analysis indicate that the right and left wheel distribution of vehicles fit normal distribution only on
DZ-1. This result showed that if a deformation zone has wider area and less depth, it will be less effective on lateral lane utilization of vehicles. It is also concluded that both expected right and left wheel positions of vehicles do not fit normal distribution on examined lane surfaces. It indicates that there are clear deviations between the expected lateral positions and the current positions of vehicles on deformation zones. The most significant factor on the magnitude of the deviations is found as the magnitude and the position of deformations on straight sections of a road. It is also concluded that variation in other parameters such as deformation type, depth and height are associated with the lateral lane utilization of drivers. 
In terms of longitudinal lane utilization and driving behaviour analysis, standard deviation values of the vehicle speeds were found significantly higher considering the non-deformed section of the road. This indicates that vehicles travel more stable in non-deformed zones with respect to deformed zones. While the data were investigated considering five different driver types, it is seen that the speed values and the corresponding standard deviations obviously differ from each other. The analysis shows that DZ-2 is subject to the greatest speed variations among all deformation points. Because, DZ-2 has three deformation point and three different deformation type. In addition, results indicate that the 2nd driver has the highest standard deviation of the speed, and it shows that 2nd driver exhibits an aggressive driver characteristics. In the light of findings, it is possible to consider that the driver characteristics such as perception and aggressiveness are seen as the most important factors influencing the longitudinal vehicle behaviours while passing through the deformation zones. Additionally, it is seen, that surface deformation has negative effect on traffic safety, fuel consumption and road surface durability.

In future studies, the longitudinal and lateral movements of vehicles on a deformed road can be investigated especially in the light of more extended data. The future studies need to reflect and clarify different measurement methods and to suggest further ways to estimate the effect of road surface deformations on the lateral lane utilization. Additionally, current lane shift models could be calibrated with actual observation and questionnaire data. Thus, lateral positions and longitudinal driving behaviours of vehicles on a road with deformations could be related to a mathematical model easily. In this manner, both implementing a mathematical model and calibration of an available model with the real observation data can be performed.

\section{References}

Aydın, M. M.; Yildirim, M. S.; Karpuz, O.; Ghasemlou, K. 2014. Modeling of driver lane choice behavior with artificial neural networks (ANN) and linear regression (LR) analysis on deformed roads, Computer Science \& Engineering: An International Journal 4(1): 47-57. http://doi.org/10.5121/cseij.2014.4105

Aydın, M. M. 2013. Çok Şeritli yollarda sürücü şerit seçim davranışlarının modellenmesi. Yüksek Lisans Tezi, Dokuz Eylül Universitesi, Fen Bilimleri Enstitüsü, Izmir, Turkey. 126 s. (in Turkish).

Aydın, M. M.; Topal, A.; Tanyel, S. 2013. Çok şeritli yollarda yol yüzey bozukluklarının sürücü davranışları üzerindeki etkisinin incelenmesi, TMMOB 10: Ulaştırma Kongresi, 25-27 Eylül 2013, İzmir, Turkey, 413-425. (in Turkish).

Battiato, S.; Rizzo, L.; Stanco, F.; Cafiso, S.; Di Graziano, A. 2006. Pavement surface distress by using non-linear image analysis techniques, in Proceedings of SIMAI 2006, 22-26 May 2006, Baia Samuele, Ragusa, Italy, 1-4.

Ben-Edigbe, J. 2005. Influence of Pavement Distress on Capacity Loss and Their Implications for PCE: a Thesis Submitted for the Award of Doctorate Degree of Philosophy. University of Strathclyde, Glasgow, UK. 283 p.
Ben-Edigbe, J. 2010. Assessment of Speed-Flow-Density Functions under Adverse Pavement Condition, International Journal of Sustainable Development and Planning 5(3): 238-252. http://doi.org/10.2495/SDP-V5-N3-238-252

Ben-Edigbe, J.; Ferguson, N. 2005. Extent of capacity loss resulting from pavement distress, Proceedings of the Institution of Civil Engineers - Transport 158(1): 27-32. http://doi.org/10.1680/tran.158.1.27.57830

Ben-Edigbe, J.; Mashros, N.; Minhans, A. 2011. Exploration of trapezoidal flowrate contractions resulting from pavement distress, Journal of Emerging Trends in Engineering and Applied Sciences 2(2): 351-354.

Dell'Acqua, G.; De Luca, M.; Lamberti, R. 2011. Indirect skid resistance measurement for porous asphalt pavement management, Transportation Research Record: Journal of the Transportation Research Board 2205: 147-154. http://doi.org/10.3141/2205-19

Gunay B. 2001. An overview of the lateral properties of road traffic flow, Traffic Engineering \& Control 42(11): 401-405.

Gunay, B. 2004. An investigation of lane utilisation on Turkish highways, Proceedings of the Institution of Civil Engineers Transport 157(1): 43-49.

http://doi.org/10.1680/tran.2004.157.1.43

Gunay, B. 2008. A methodology on the automatic recognition of poor lane keeping, Journal of Advanced Transportation 42(2): 129-149. http://doi.org/10.1002/atr.5670420203

Gunay, B. 2009. Rationality of a non-lane-based car-following theory, Proceedings of the Institution of Civil Engineers Transport 162(1): 27-37. http://doi.org/10.1680/tran.2009.162.1.27

Gunay, B.; Woodward, D. 2007. Lateral position of traffic negotiating horizontal bends, Proceedings of the Institution of Civil Engineers - Transport 160(1): 1-11. http://doi.org/10.1680/tran.2007.160.1.1

Khan, S.; Maini, P. 1999. Modeling heterogeneous traffic flow, Transportation Research Record: Journal of the Transportation Research Board 1678: 234-341. http://doi.org/10.3141/1678-28

Lee, H. D.; Kim, J. J. 2005. Development of a Manual Crack Quantification and Automated Crack Measurement System. Project TR-457 Final Report. University of Iowa, US. 21 p. Available from Internet: http://publications.iowa. gov/2423/1/tr457.pdf

Leutzbach, W.; Wiedemann, R. 1986. Development and applications of traffic simulation models at the Karlsruhe Institut fur Verkehrwesen, Traffic Engineering \& Control 27(5): 270-278.

Nagel, K.; Schreckenberg, M. 1992. A cellular automaton model for freeway traffic, Journal de Physique Archives 2(12): 2221-2229. http://doi.org/10.1051/jp1:1992277

TRB. 2004. Automated Pavements Distress Collection Techniques: a Synthesis of Highway Practice. NCHRP Synthesis 334, National Cooperative Highway Research Program (NCHRP). Transportation Research Board (TRB), Washington, DC. 94 p. Available from Internet: http:// onlinepubs.trb.org/onlinepubs/nchrp/nchrp_syn_334.pdf

Oloufa, A.; Mahgoub, H.; Ali, H. 2004. Infrared Thermography for asphalt crack imaging and automated detection, Transportation Research Record: Journal of the Transportation Research Board 1889: 126-133.

http://doi.org/10.3141/1889-14

Strazdins, G.; Mednis, A.; Kanonirs G.; Zviedris, R.; Selavo, L. 2011. Towards vehicular sensor networks with android smartphones for road surface monitoring, in The Second 
International Workshop on Networks of Cooperating Objects (CONET'11): Electronic Proceedings of CPSWeek'11, 11-14 April 2011, Chicago, US, 1-4.

Tanyel, S.; Caliskanelli, S. P.; Aydın, M. M.; Utku, S. B. 2013. The investigation of heavy vehicle effects on roundabouts, Teknik Dergi 24(4): 6479-6504.

Timm, D. H.; Priest, A. L. 2005. Wheel Wander at the NCAT Test Track. NCAT Report 05-02. Auburn University, Auburn, AL. 32 p. Available from Internet: http://www.eng. auburn.edu/research/centers/ncat/files/reports/2005/ rep05-02.pdf

Ross, A.; Baguley, C.; Hills, B.; McDonald, M.; Silcock, D. 1991. Towards Safer Roads in Developing Countries: a Guide for Planners and Engineers. Transport Research Laboratory (TRL), Crowthorne, England. 232 p.

Yousif, S.; Al-Obaedi, J.; Henson, R. 2013. Drivers' lane utilization for United Kingdom motorways, Journal of Transportation Engineering 139(5): 441-447. http://doi.org/10.1061/(ASCE)TE.1943-5436.0000531

Walker, D.; Entine, L.; Kummer, S. 2002. Pavement Surface Evaluation and Rating: Asphalt PASER Manual. Transportation Information Center, University of Wisconsin-Madison, US. 32 p. Available from Internet: http://epdfiles.engr. wisc.edu/pdf_web_files/tic/manuals/asphalt-paser_02_ rev13.pdf

Žilioniené, D.; De Luca, M.; Dell'Acqua, G. 2013. Evaluation of climatic factors based on the mechanistic-empirical pavement design guide, The Baltic Journal of Road and Bridge Engineering 8(3):158-165.

http://doi.org/10.3846/bjrbe.2013.20 